\title{
A critical evaluation of mathematics courses in architectural education and practice
}

\author{
Seniz Cikis
}

Published online: 12 August 2008

(C) Springer Science+Business Media B.V. 2008

\begin{abstract}
Mathematics courses are integral part of architectural education. The content and objectives of these courses were determined in the Age of Enlightenment. Although conditions have changed since then, they still exist without being subjected to a radical revision. This study aims to introduce the necessary information for upgrading the content of mathematics courses to contemporary conditions. On these grounds, the historical conditions when these courses were first considered within architectural education are classified and then the content of existing mathematics courses are examined. Finally, the effects of mathematics and mathematics courses on the epistemology of the profession are scrutinized.
\end{abstract}

Keywords Applied mathematics - Architectural education - Arts and mathematics · Curriculum of architecture - General mathematics · Mathematics courses ·

Mathematics in higher education

\author{
Abbreviations \\ EAAE European Association of Architectural Schools \\ ACSA Association of Collegiate Schools of Architecture
}

Main roles of higher education institutions in the social division of labor are to rationalize professional process, to provide professional education, to raise professionals equipped with modern ideas and to produce scientific knowledge. Science has a critical role in meeting all these expectations imposed by a positivist world view. The extension of scientific thinking into a broader sphere of culture brings architecture and its education itself close to mathematics and thus into the stream of productive thinking (Vesely 2004, p. 23). The first architectural schools that were established during the eighteenth and nineteenth centuries had developed their curriculum and mathematics courses under the

S. Cikis $(\bowtie)$

Department of Architecture, Izmir Institute of Technology, Izmir 35430, Turkey

e-mail: senizcikis@iyte.edu.tr 
influence of these ideas. The content of these courses is still relevant has not been subjected to any comprehensive revision since the beginning of their use. But, it is necessary to interrogate the use and the necessity of mathematics courses that are recognized as a sine qua non component of architectural education. This interrogation would also be the precondition of any revision attempt that is postponed because of the contradictory situation between consistency of modern higher education tradition and changing professional requirements. Today, we all know that mathematics is vital for human culture as well as architects. We also know that any extra or redundant mathematical knowledge or course does not disrupt the creativity or competency of architects in their professional practice. This essay does not argue for the elimination of the mathematics courses, but an upgrading of their content considering their function in both contemporary educational and professional necessities.

The problem of content, which has so far been presented as a hypothesis, must now be defined. For this purpose, the content of mathematics courses will firstly be classified, and then current statistical data relating to mathematical education will be presented. Finally, the function of mathematical subjects in the architectural profession will be questioned. In light of all this information, the logic of a revision of the role and necessity of mathematics in the architectural curriculum will be presented.

\section{Classification of mathematics courses in architectural education}

The relationships between mathematics and architecture, formed in line with the missions of higher education mentioned above, answer three basic functions. Firstly, general mathematics courses are aimed at the training of a professional; secondly, productionoriented mathematics are aimed at rationalizing architectural production processes; lastly, design-oriented mathematics are aimed at rationalizing architectural design processes. In the following sections, the historical framework of these mathematical subject groups is given and their contents are deciphered. The first group comes from general university education, the second from engineering education and the third from a retrospective evaluation of various periods of architectural history. ${ }^{1}$

\section{General mathematics courses}

One of the main objectives of the modern university education system is to train individuals who embody a positivist word view. Because of this expectation, general education courses are an integral part of higher education institutions. In most university programs, general education lies somewhere along the continuum between perennialism, essentialism and progressivism. Perennialists believe that education should be centered primarily with training the rational mind. According to essentialists, general education should based upon an essential prescribed body of knowledge dealing with human heritage. Progressivism focuses on life experiments. It is problem oriented and not subject matter based (Bunch 1993, pp. 51-52).

Representing the material world through mathematics and producing knowledge by this means is the most indirect way of appropriating and disseminating a positivist world view.

\footnotetext{
${ }^{1}$ Classification of the functions of mathematics courses are realized by the evaluation of the curricula and course contents of the following 19th century architectural schools: École Polytechnique, École Central in Paris, École des Beaux-Arts.
} 
The main function of mathematics courses is to partly fulfill this function; in other words, to provide an infrastructure that can adapt mathematical rules to a conceptual world. For this reason, mathematics courses have been given a place in education in most periods of history and at almost all levels. From this point of view, general mathematics courses have perennial peculiarity and are structured for a reproducing rational world view. However, the standardization of these courses allowing for their application in all fields of engineering education was first envisaged and implemented in the École Polytechnique and École Central in Paris. These two schools advocated impersonal lectures and the notion of required subjects that everyone had to master before specializing in a field of applied sciences. Thereafter, this came to be the dominant pedagogical idea in professional education (Pérez-Gomez 1996, p. 278).

Such mathematics courses, still given in nearly all institutions of higher education, are generally called calculus, but also consists of topics such as differentiation, integration, equations, number theory, functions, derivatives, vectors, and plane and solid geometry. The composition of these mathematics lessons and their level of instruction are adapted according to the particular requirements of each scientific/professional field. For example, in professions inclined to mass production and those positivistic fields like the applied sciences, engineering and statistical economics, mathematics is dealt with in a much more comprehensive and advanced way. ${ }^{2}$ This method originated from a desire to create a scientific foundation at a very high level, since mathematics has a wide field of application in these professions. Another reason for increasing the value placed on the teaching of mathematics in the early years of higher education is its direct contribution to other basic scientific courses such as physics, chemistry, biology and other courses given at later stages. However, perhaps the most important reason why general mathematics exists in the scientific curriculum is that it forms individuals with those scientific qualities demanded by the modern world (Habermas 1970, pp. 62-122).

Such thinking lies at the heart of the acceptance of mathematics as an important element in the curriculum of basic science courses, and why the level of the mathematics courses provided in higher education programs is generally much higher than that required by professional practice. Contrary to engineering or basic science departments, calculus lessons traditionally given in schools of architecture are limited and simple. In some schools, it is provided under headings like pre-calculus or introductory calculus, and the course content is generally limited to topics like limits, derivatives, integrals and functions. ${ }^{3}$

\section{Production-oriented mathematics}

As described above, general mathematics courses are designed for the training of professionals and are expected to be indirectly influential. In comparison, mathematics courses addressing building production aim to be a basis that enables the construction of an architectural product. These courses, which are given under the heading of "applied mathematics" and/or "descriptive geometry," aim at guaranteeing the continuation and universality of architectural production conditions. Descriptive geometry, which forms a main part of production-oriented mathematics, is the practical application of Euclidean

\footnotetext{
${ }^{2}$ See Thomas (1960), as a typical example of a general mathematic course book. This book is still one of the most common source books on the field of basic and applied sciences.

3 See, for example, course descriptions at the University of Illinois at Urbana Champain, School of Architecture (http://courses.uiuc.edu/cis/catalog/urbana/2007/Spring/MATH/index.html). Calculus courses are limited to the subjects of functions, pre-calculus, derivative and integral.
} 
geometry. It was first formulated by Girard Desargues and Blaise Pascal in the 17th century and was later adapted for formal teaching by Gaspard Monge in the 18th century. Such lessons, which were subsequently given in the engineering and architecture departments at the École Polytechnique at the suggestion of Monge (who was one of the school's founders), became the core science in the canon of subjects maintained by the Polytechnique. The division of subjects and their allocation within a curricular system imbued with mathematics, as well as the simultaneous arrangement of the entire canon in coherence with an instructive and illustrative discipline that made a practical application of the theoretical principles of all then existing branches of engineering possible (including architecture), was Monge's invention (Pfammatter 2000, p. 24).

Although various topics have occasionally been added to or subtracted from productionorientated courses, in general there has been a continuity. The main reasons for this continuity is that the building production field uses components and connections based on Euclidean geometry. Another reason is that until recently analogue methods based on Euclidian geometry were used a design tool. In time, it is possible that the currently developing digital production methods and design processes will make Euclidean postulations and mathematics subjects linked to geometric projection more irrelevant, or at the very least more deficient.

Mathematics subjects, which were first introduced in architectural schools established in France and later The Bauhaus and similar schools, are generally considered to represent the origin of modern architectural education tradition, since today they appear almost everywhere. Today, just as in the past, production-oriented mathematics, encountered under the heading of descriptive geometry and applied mathematics, also include topics such as derivatives and integration because these form the basis of structural calculations. ${ }^{4}$ Descriptive geometry is given to all those professions based on production, as well as the applied sciences. Such topics are especially accepted as an inseparable part of the early years of engineering education. ${ }^{5}$ Applied mathematics includes mathematical knowledge used in structural calculations, one of the main activities of structural engineers, and is included in the architectural curriculum to enable graduates to be more effective in the process of calculation when the two professions are in intense interaction. In fact, this situation can be interpreted as more of a one-sided information exchange: mathematics courses addressing building production brings architectural students closer to the information sphere and language of engineers, specifically structural engineers, and for this reason are presented as simplified adaptations of topics covered in an engineering education.

\section{Design-oriented mathematics}

Building production and building design are the two important activities of the architectural profession. Traditionally, however, design has come to the forefront as the more prestigious activity, the result of a strategic preference expressed as early as the Age of Enlightenment: the rationalization of the design process (Gutman 1988, p. 61). The idea

\footnotetext{
${ }^{4}$ See, for example, the list of the regular course descriptions at Czech Technical University, Faculty of Architecture (http://web.cvut.cz/en/fa/regular_courses.html). Mathematics (applied) course covers the use of mathematical methods in the subjects of building physics, statistics and planning. On the other hand, descriptive geometry courses focus on spatial imagination and graphic abilities, and deals with theory and practice.

5 See Paré et al. (1977), as a typical course book in engineering departments.
} 
that the unity of aesthetics, design and mathematics, in other words the belief that beautiful design can be expressed with mathematical rules, was also in line with this logic. Developments in this direction were first expressed on an institutional level in the field of architectural education at the French Royal Academy and followed by schools like the École des Beaux-Arts, where established canons formed a primary source of information and design studios were run according to classical codes adapted to fixed tectonics. ${ }^{6}$ According to this educational model, the geometrical analysis of classical buildings was important in supporting design studios. For this reason, such schools offered mathematics classes that taught the analysis, as well as the general rules, of the classical buildings of Ancient Greece, Rome, the Renaissance and Baroque Ages. In this school of thought, descriptive geometry was taught in the context of architectural presentation, with topics such as proportion, balance, symmetry and laws of harmony given more importance. In this way, in parallel to the general approach of the schools, strong links were formed between architectural history, design and mathematics (Moor 1977, pp. 145-174).

However, in our contemporary architectural higher education system, where creativity is reached through diversity and is based on individual challenge rather than on conventions, there is no practical benefit to design studios carrying out historical retrospective detailed studies. In all programs shaped by this educational view still prevalent today, the instruction of such topics as laws of harmony, proportions, symmetry and the geometrical analysis of historic buildings do not carry primary importance in developing students' design abilities (Whitford 1991, p. 200). On the contrary, if an architectural education is considered as a whole, these topics would lead to inconsistencies in a system where diversity in design is envisioned. For this reason, ever since The Bauhaus education model became prevalent, design-oriented mathematics subjects have not been included in the curriculum as a compulsory course. ${ }^{7}$ Even when not included in architectural school curricula, templates where the relationship between aesthetics, architecture and mathematics, as in the version shaped by the French Royal Academy and the École des BeauxArts still continue to be considered valid. ${ }^{8}$

\section{Analysis of mathematics courses in architectural schools}

How loyal are contemporary architectural schools to the tri-partite formulation summarized above? Which types of mathematics are excluded, to what extent, and which are subject to modification? A statistical survey carried out within the scope of this article in order to find answers to these questions has at the same time provided an opportunity to establish the functions of mathematics with regard to architecture and its education. The necessary data has been collected from the official internet websites of the selected schools of architecture, which generally include catalogs and course descriptions of courses pertaining to professional training leading to graduate degrees in architecture. The individual schools or

\footnotetext{
${ }^{6}$ See Egbert (1980), for the further information about the educational and pedagogical approaches of the Beaux-Arts School.

7 Today, design oriented mathematics courses are mostly in elective courses. For example, a course entitled Mathematics in Architecture, which is given at Middle East Technical University Department of Architecture is designed to teach the basics of mathematical concepts and principles in architecture provided together with several examples to students in order to cope with design problems in architecture. (http://www.archweb.metu.edu.tr/programs/index_undergraduate.htm).

8 See Kappraff (1991), one of the most popular books exemplifying canonic approaches in between mathematics and architecture, which also includes 19th century approaches.
} 
departments that were randomly selected were acquired from members listed on the official websites of the Association of Collegiate Schools of Architecture (ACSA) and European Association of Architectural Schools (EAAE). Statistical analyses of the data also includes the evaluation of contents of curricula and course descriptions from all selected programs. After reading course descriptions to determine equivalence between selected architecture schools/departments, the courses were grouped according to their contents.

This study presents an evaluation of relevant curricular information from institutions of higher education in Europe and North America, the origin of modern architectural education where various types of educational models are represented. Therefore, in a study directed towards the evaluation of architectural curricula, case studies from schools in these regions were considered a correct choice in terms of the representativeness of the results. Member institutions of the EAAE and the ACSA, the two oldest organizations with the widest participation amongst other western architectural schools associations, fit the selection criteria. According to data gathered in November 2006, the membership of the European Association of Architectural Schools ${ }^{9}$ stands at 146 while that of the Association of Collegiate Schools of Architecture ${ }^{10}$ is 124 . Fifty-three architectural schools, $20 \%$ of the total membership of these two organizations, were chosen at random for this study, which was not limited by the content of their mathematics courses but also considered their place and weighting in the general curriculum. ${ }^{11}$

\footnotetext{
9 The EAAE counts more than 100 Active Member Schools in Europe from the Canary Islands to the Urals, representing almost 5,000 tenured faculty members and more than 100,000 students of architecture from the undergraduate to the doctoral level. The association is building up associate memberships every year. That is why the number of associate membership is taken according to numbers of the year of 2006, when the research was conducted.

${ }^{10}$ The school membership in ACSA has grown from 10 charter members to over 250 schools in several membership categories. These include full membership for all accredited programs in the United States and government-sanctioned schools in Canada. Through these schools, over 5,000 architecture faculty are represented. ACSA currently has 125 full members: 115 in the United States and 10 in Canada. The number of associate membership was taken according to the numbers of the year 2006, when this research was conducted.

${ }^{11}$ List of the selected schools: ACSA MEMBERS: University of Illinois at Urbana Champaign (School of Architecture), University of Miami (School of Architecture), Illinois Institute of Technology (College of Architecture), Georgia Institute of Technology (College of Architecture), Kansas State University (Department of Architecture), University of Washington (College of Architecture and Urban Planning), Texas Tech University (College of Architecture), Cornell University (Department of Architecture), Iowa State University (College of Design), California State Polytechnic University (Architecture Department), Clemson University (School of Architecture), Pratt Institute (Architecture Department), Hampton University (Department of Architecture), New Jersey Institute of Technology (School of Architecture), Carnegie Melon University (School of Architecture), Arizona State University (School of Architecture and Landscape Architecture), University of Houston (College of Architecture), Kent State University (College of Architecture and Environmental Design), University of Florida (School of Architecture), New York Institute of Technology (School of Architecture and Design), Washington State University (College of Engineering and Architecture), University of Nevada (School of Architecture) EAAE MEMBERS: Ecole d'Architecture de Paris la Villette (France), University of Dundee (UK), Brno University (Czech Republic), Sofia University of Architecture, Civil Engineering and Geodosy (Bulgeria), Institut Superieur d'Architecture de St-Luc (Belgium), Ecole d'Architecture de Paris Val-de-Seine (France), Moscow Architectural Institute (Russia), Universitat Politecnica de Catalunia (Spain), Liverpool John Moores University (UK), University Prishtine, Czech Technical University in Prague (Czech Republic), Szczecin University of Technology in Gliwice (Poland), Fachhochschule Darmstadt (Germany), ETH Zurich (Switzerland), Universitat Kaiserlautern (Germany), Technische Universitat Dresden (Germany), Universitat Karlsruhe (Germany), Technischen Universitat Graz (Austria), Hogeschool Antwerpen (Belgium), Universidade Moderna Setubal (Portugal), Ecole d'Architecture de Grenoble (France), Cluj Napoca Technical University (Romania), Helsinki University of Technology (Finland), Universidad Europea de Madrid (Spain), Middle East Technical University (Turkey), Universite Catholique de Louvain (Belgium).
} 
According to the National Council of Architectural Registration Boards (NCARB), mathematics can be described as the logical study of quantity, form, arrangement and magnitude. It includes the methods for rigorously using defined self-consistent symbols to disclose the properties and exact relationships of quantities and magnitude either in the abstract or in their practical applications. Acceptable courses in architectural schools include algebra, analytic geometry, calculus, differential equations, linear algebra, trigonometry and all courses for which calculus is a prerequisite (National Council of Architectural Registration Boards 1990, p. 7). Approximately 85\% of the member schools examined provide mathematics courses (as defined above) in their curriculum. These mathematics courses, which on average comprise $15.54 \%$ of first year credits, are generally distributed over two semesters. Five major course groups have been identified in the first year curricula of the selected schools. These were: general, mathematics, history and theory courses, construction and drawing, and introductory design courses. In terms of credit weighting, mathematics comes after subjects such as design studio, construction/ materials, structure, and history and theory courses and is amongst the basic subjects and general courses such as languages, physics, and sports. Of the $15 \%$ of architectural schools that do not have mathematics in their curriculum, some require high school level mathematics, while others demand no prerequisites (Fig. 1).

The content of mathematics courses in architecture departments may take on names such as mathematics, advanced mathematics, descriptive geometry, pre-calculus, calculus, applied mathematics, algebra, geometry and/or trigonometry. Of the schools investigated, $47.1 \%$ provide at least two of these. At $66 \%$, calculus is the most widespread mathematics subject provided, followed by descriptive geometry at $30.1 \%$, geometry and analytical geometry at $11.3 \%$, applied mathematics at $5.6 \%$ and trigonometry at $1.8 \%$. Schools providing at least two mathematics subjects usually concentrate on the pair of calculus and descriptive geometry, followed by calculus and applied mathematics (Fig. 2).

The provision of mathematics also shows variation according to region. For example, according to the results of the survey of EAAE member schools, 55.2\% provide descriptive geometry. In contrast, of the chosen ACSA member schools, none provide this subject, offering calculus instead at the rate of $87.5 \%$ (Fig. 3).

The most general conclusion that can be drawn from this study is that architectural school mathematics courses in North America and Europe are concentrated under the headings of calculus, analytical geometry, descriptive geometry and applied mathematics. When grouped according to function, amongst these topics calculus and analytical geometry are within the scope of "general mathematics," while descriptive geometry and applied mathematics are within the scope of "production-oriented mathematics". $77.3 \%$ of the architectural schools studied provide general mathematics lessons while $35.6 \%$ provide

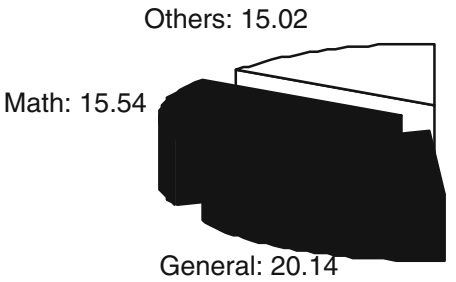

General: 20.14

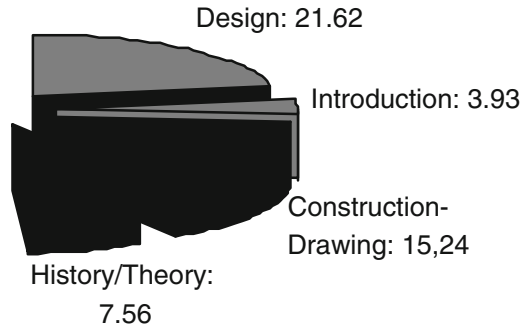

7.56

Fig. 1 Distribution of course loads in first year education 


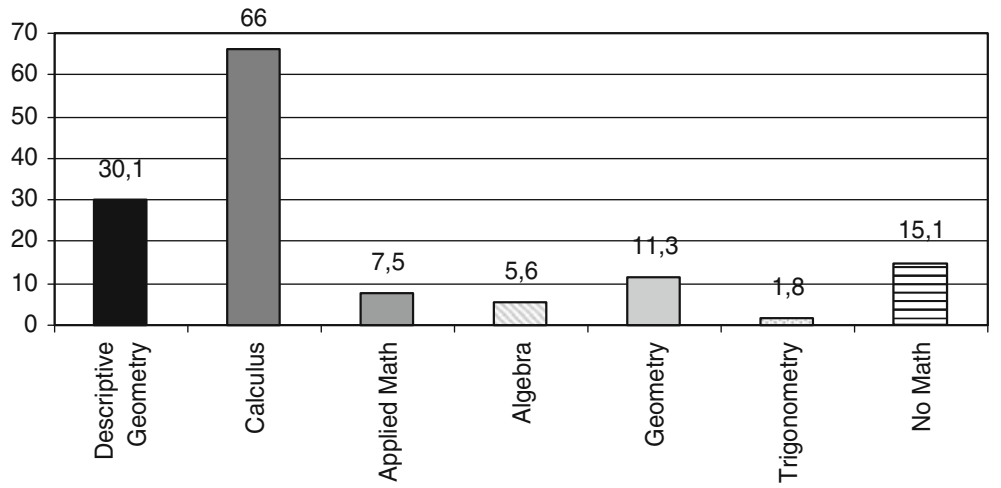

Fig. 2 Distribution of mathematics courses according to course title

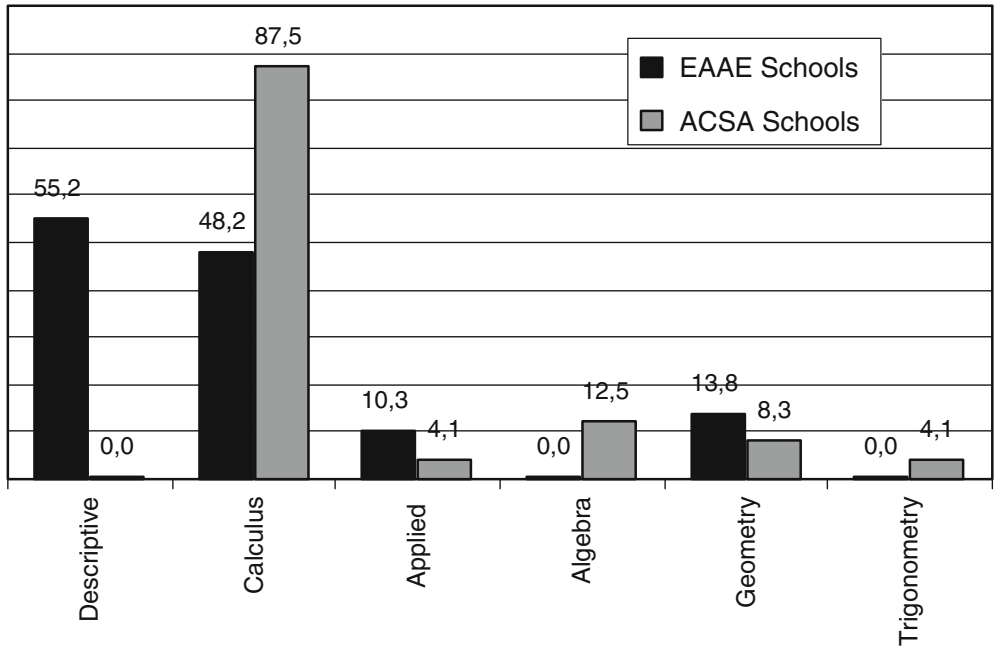

Fig. 3 Distribution of mathematics course title according to location

production-oriented mathematics. If one considers that almost half of the schools investigated provide at least two different mathematics courses, these two approaches are still valid, at least in the field of education. Also, despite a collective belief as to their validity, "designoriented mathematics" seems to have been abandoned.

\section{The role of mathematics in architectural epistemology}

Although mathematics is being provided in architectural education today, what kind of a function does it have in architectural practice or architects' common knowledge domain? An answer to this question is closely linked to the basic functions of professional educational institutions, one of which is to rationalize professional practices. Therefore, they also indirectly shape the professionals. For example, Mies van der Rohe once indicated this function of education by claiming that "the business of education is to implant insights and 
responsibility. It must turn irresponsible opinion into responsible judgment and lead from chance and arbitrariness to the rational lucidity of an intellectual order" (Rybczynski 1992, pp. 273-274). Although the factors shaping professional process are varied, the primary purveyor of professional knowledge, both tacit and explicit, is the academy. In academic terms, professional schools dominate the production of producers (Cuff 1992, p. 43). This role taken on by educational institutions, consciously or unconsciously, is largely due to the effort to standardize knowledge, which provides the common language and the tacit knowledge that distinguishes professionals from lay persons. It is, in fact, the main support of a professional sub-culture (Larson 1977, p. 44). This sub-culture, which empowers professionals against society, not only contains practical knowledge, but also contains common topics, jargon, terminology and beliefs which have no specific function in terms of practice, but are none-the-less shared by all professional architects. For this reason, it is possible for certain topics that form a common culture or training to be included in a curriculum, even though such topics do not have any specific place in the application of the profession. The existence of any topics that are beyond this scope, including mathematics, should be met with skepticism since a vocabulary of architecture is needed for the professionals, without need to define it over and over (Pollak 1997, p. 268).

In fact, occupations become professionalized when they create legally sanctioned jurisdictional frameworks to admit, control and differentiate their practitioners. Central to this occupational framework are several distinctive characteristics that distinguish professionals from occupations. First there is a professional claim to exclusive and expert knowledge. Moreover, this assertion is corroborated by prescribed education and training requirements (Saunders 1996, p. 8). On the other hand architects have never agreed about the profession's core or specialized domain. The artistic and ideological foundations of the field justify architects' claim that they possess ecumenical proficiencies and knowledge (Blau 1988, p. 6). Architectural education, due to the nature of the profession, must give place to knowledge that serves the communication of the profession, since it has chosen a design-based field of application. Considering that standardizing and rationalizing the knowledge and skills pertaining to the act of design is not only impossible but also undesirable, it is quite natural for topics that would in any way nurture it to be included within the circulation of the profession. ${ }^{12}$ For example, when compared to engineering or medicine, in architectural education more emphasis is given to topics such as history and philosophy. When these courses, which do not provide any direct benefit to the praxis of the profession, are considered, it is important that they provide general conventions and information enters into circulation. Thanks to this sharing, the general canonic knowledgebase of the profession is widened-something that not only means the profession gains more strength in society but also gives new dimensions to communication within the profession. In other words, the widening of the common knowledge-base not only allows the development of inter-personal communication but it also nourishes design activitiesthose considered to be the most prestigious field of the profession. For example, a common use of jargon or knowledge while developing symbolic production and thought processes through concepts simultaneously eases inter- and intra-professional communication. In this

\footnotetext{
12 See Larson (1977). According to Larson, the knowledge that is required for performing any profession has two different dimensions as cognitive and normative. The cognitive dimension is centered on the body of knowledge and techniques, that the professional applies in their works. The normative dimension covers the service orientation of professionals and their distinctive ethics, beliefs and manners that justify the privilege of self regulation granted to them by society. In the profession of architecture, the normative dimension of professional knowledge is very important since design activities cannot be reduced to rationalised processes.
} 
way, it allows for new channels to open up in the professional aspects of both design and communication (Medway 1994, p. 103).

The common knowledge base of architectural profession does not consist of inevitable knowledge necessary simply for it to be realized, as is typical in other branches of modern art and design. But just like an artist, the modern architect searches for a reason that will convince him/her that he/she ought to feel one way and not the other. The architect thus tries to expose him/herself to conditions that are not conventional or traditional but inevitable for himself, to conditions that exist apart from arbitrary likes and dislikes, to forces at work in the world that produce inevitable effects that are not distorted by arbitrary preferences. ${ }^{13}$ In contemporary architectural practice, architectural design and creativity that places design activities at its center, apart from tradition and conventions, has been defined as practice based on individual challenge. Under these circumstances, especially during the period when modern architecture was being initially formulated, "function" was defined as an untarnished and inevitable force (Hubbard 1980, pp. 5-6). During the period immediately preceding this modern formulation, the late 18th and 19th centuries (the same time when architectural education was being transferred to modern educational institutions), it was premeditated that geometry and mathematics would become one of the dependable tools in the collective knowledge base of the profession capable of compensating inadequacies due to individuals. It must also be added that the disciplines that architecture has always referred to, placed trust in and attempted to use their methods or information is not limited to mathematics alone. Architecture also consults the social sciences, the natural sciences, various fields of engineering, music, philosophy and other fields of art.

Regardless of its function, the choice of whether mathematics should be a part of the canonic knowledge-base of the architectural profession must be carefully considered; otherwise, it would have the drawback of remaining in the curriculum as an unnecessary burden. In order for the communication within the profession to function healthily, certain topics are required to be consistently presented. Although this requirement may in the long term lead educational institutions to display a conservative approach, it creates opportunities for professionals have common denominators. For this reason, it is possible for many courses which have not been revised ever since the beginnings of the modern education tradition to remain in the curriculum along with those courses whose content and methods have been updated.

For example, although there are many alternatives in the periods and regions covered in history of architecture courses, such courses form a very important component of the standard knowledge-base of the profession. Alternative history of architecture courses are shaped by taking a position against this background. ${ }^{14}$ Similarly, despite some exceptions, in most parts of the world "foundation design", "basic design" or "introduction to architectural design" courses are a continuation of the Bauhaus tradition established in the first quarter of the 20th century, whose basic aesthetic philosophy was established on Gestalt principles and industrial production. The terminology and visual reparatory of such first-year studio courses has not changed much since the Bauhaus, but this seems not to be

\footnotetext{
${ }^{13}$ Hubbard describes conventional and inevitable as follows: there are those things we accept as being the way they are because we have no choice but to do so, and there are those things we accept as being the way they are because we want them to be that way. The first category of things are inevitable and the second conventional.

14 See Baydar (2000), for an alternative historiography of architecture.
} 
a problem since they are not only a part of the education but also a part of our common culture.

Similarly, it is widely thought that mathematics topics form a part of common professional knowledge and culture, most probably due to the perception that we, as architects, have resorted to our mathematical knowledge throughout various stages of history and increasingly see it as a natural tool of the profession. With the rise of a positivist world view, mathematical-architecture relationships, which with computers are entering a new phase in terms of realization (though not in methods), maintains its relevance in our minds today (as a prejudice), even if they are in actual fact not relevant. The fact that such courses exist in $85 \%$ of North American and European architectural school curricula with contents shaped in the 19th century is proof that this mindset is still relevant. However, what is contradictory in this relationship is that despite our common belief that mathematics possesses important functions in terms of architecture; we do not share its knowledge-base or give it prominence in professional practice. If this were to be expressed in professional architectural epistemological terminology, we would not require its knowledge-base because we do not need mathematical knowledge, neither in the cognitive nor normative sense. The knowledge of mathematics required by an ordinary architect to carry out his/her profession is at quite a simple level and, unless a very special situation arises, an architect can carry out all sorts of professional duties without resorting to any higher mathematical knowledge. For this reason, any special mathematical knowledge gained in architectural school is usually quickly forgotten. It is this state of uselessness that lies beneath architects' incompetence of mathematics, despite being educated in the subject.

\section{Conclusion}

It is evident that mathematical-architecture relationships, the foundations of which are rooted in the Age of Enlightenment, have brought with them many of their own problems-both philosophical and in content. This relationship, which is fraught with problems, becomes even more complicated due to certain sensitivities that occasionally come to the fore in education or society. For example, rising social interest during the 1960s was concerned with sociology rather than building construction. The 1970s, in reaction to this radicalism, saw a revival of interest in architectural history and also in the design of everyday buildings, accompanied with beautifully rendered drawings, up to Beaux-Arts standards. Taken together with the rising individualism of the 1990s, all such changes impose a new set of relations between mathematics and architecture, since there are no longer universally accepted rules for the designing of buildings (Rybczynski 1992, pp. 273-274).

Apart from such problems awaiting a solution, the need for these mathematicalarchitectural relationships to adapt to new recently developing digital production modes is another dimension of this subject. It seems inevitable that these relationships should be overhauled because computer and information technologies have come to affect architecture just as in the other areas in our lives. With the development of vector based software, founded on other areas of mathematics, a new understanding of geometrical construction based on topological operations has come to the forefront, creating the possibility of carrying out operations which do not depend on Euclidean geometry. By way of such operations carried out on the computer, it is possible to articulate complex forms such as multiple curvatures that are formed by progressing curvatures, make them immediately visible and express them mathematically and to convey this information quickly to storage. 
The opportunities afforded by digital technologies have at the same time lead to the demise of the normative foundations of modern architecture such as standardization, mass production and even the validity of the Cartesian understanding of space. In this way, digital technologies are, both conceptually and scientifically, initiating a brand new age. On the other hand in both offices and schools, the use of relatively new, and continually renewed, digital technologies have transformed the design process in varying degrees, putting into question the traditional techniques of the profession. In architectural offices it has led to a heightened demand for digital skills, and in the schools the use of software programs, and their attendant aesthetics, has provoked a series debate over the often too common reliance on these aesthetics to generate designs (Vidler 2004, p. 14).

Digital applications, which first entered the field of architecture as purely a presentation tool, have quickly become an inseparable part of the design process. The basic reason that speeded up this process was the parallel development of the spread of appropriate software and communication technologies. These techniques and technologies can alter not only the design and presentation processes but also the educational environment, tools and even our modes of communication. This process, which has been self-propagated, has for the time being been reflected in architectural curricula by the addition of computer courses or the adaptation of these technologies to communication/representation techniques courses. Whether or not the existence of a tool that transforms the architectural communication, design and production environment in such a radical way will, in the near future, lead us to revise all curricula including mathematics in a serious manner is yet to be seen. Such a revision must be comprehensive enough to redefine the functions of mathematics in the architectural field under the framework of a new paradigm.

Although they have not yet gained clarity, these re-formed relationships are neither supported by general mathematics courses consisting of calculus nor production-oriented courses founded on Euclidean geometry. The mathematical foundation of digital technologies, which can lead to things far outreaching its numerical, geometrical or technoscientific foundation, are based on topics such as non-standard analysis, topological applications, algorithm systems, fractals or chaos theory. However, the adaptation of mathematics courses to developing digital technologies necessitates something more fundamental than the addition of these subjects to the curriculum.

Firstly, we must review our outlook of mathematics and how we make use of it, and give it new meaning and functions. For example, in an environment where the process of production and design are interwoven and the architect is able, through the opportunities offered by digital technologies, to take on effective roles in both environments similar to the Middle Ages, it will be impossible for mathematics courses oriented towards production and those oriented towards design to be separated. This would primarily invalidate the functional classification made in a covert way up to this date. ${ }^{15}$ Moreover, this would cause the relationship of design and mathematics (one that has been abandoned since the Bauhaus) to be brought onto the agenda in a non-retrospective platform.

Ironically, a significant questioning of mathematics courses in the architectural curriculum has been ignored by the very academic society whose main characteristic should be critical thinking and the questioning of norms. It is necessary for the function of mathematics courses to be re-evaluated in terms of professional education, professional practice and the culture of the profession in an unbiased way and, in turn, be re-adapted to the needs of the profession. However, while becoming more inevitable because of the development of digital technologies, such a revision is at the same time becoming more

15 See Perez-Gomez (1999), for an alternative use of mathematics in architecture. 
and more complex. Over and above the necessary technical and interpersonal skills, there are other skills that architects must possess. The rapid pace at which knowledge is growing means that they, like all other professionals, need to develop strategies to deal with new information that may be relevant to their professional development. All this implies a high degree of autonomy and flexibility in learning throughout life (Nicol and Pilling 2000, p. 6).

\section{References}

Baydar, G. (2000). Beyond lack and excess: Other architectures/other landscapes. Journal of Architectural Education, 54(1), 20-27.

Blau, J. (1988). Architects and firms: A sociological perspective on architectural practice. Cambridge: MIT Press.

Bunch, M. (1993). Core curriculum in architectural education. New York: Melen Research University Press.

Costof, S. (1977). The architect: Chapters in the history of profession. New York: Oxford University Press. Cuff, D. (1992). Architecture: The story of practice. Cambridge: MIT Press.

Egbert, D. (1980). The Beaux arts tradition in French architecture. Princeton: Princeton University Press. Gutman, R. (1988). Architectural practice. Michigan: Princeton Architectural Press.

Habermas, J. (1970). Toward a rational society: Student protest, science and politics (J. Shapiro, Trans.). Boston: Beacon Press.

Hubbard, W. (1980). Complicity and conviction: Steps toward an architecture of convention. Cambridge: MIT Press.

Kappraff, J. (1991). Connections: The geometric bridge between art and science. New York: McGraw-Hill Inc.

Kline, M. (1977). Mathematics in Western culture. Oxford: Penguin Books.

Kline, M. (1985). Mathematics for non mathematicians. New York: Dover Publications.

Larson, M. (1977). The rise of professionalism: A sociological analysis. Berkley: University of California Press.

Medway, P. (1994). The language component in technological capability: Lessons from architecture. International Journal of Technology and Design Education, 4(1), 85-107.

Moor, R. (1977). Academic Dessin theory in France. Journal of the Society of Architectural Historians, 36(3), 145-174. doi:10.2307/989053.

National Council of Architectural Registration Boards. (1990). Curricular of information report number three. Washington: NCARB Reports.

Nicol, D., \& Pilling, S. (2000). Changing architectural education. London: Taylor and Francis Group.

Paré, E., Loving, R., \& Hill, I. (1977). Descriptive geometry. New York: MacMillan Publishing.

Pérez-Gomez, A. (1996). Architecture and the crisis of modern science. Cambridge: MIT Press.

Perez-Gomez, A. (1999). Hermeneutics as discourse in design. Design Issues, 15(2), 71-79.

Pfammatter, U. (2000). The making of the modern architect and engineer. Berlin: Birkhauser Publishers.

Pollak, M. (1997). Education of the architect. Cambridge: MIT Press.

Rybczynski, W. (1992). Looking around. New York: Penguin Books.

Saunders, W. (Ed.). (1996). Reflections on architectural practices in nineties. New York: Princeton Architectural Press.

Thomas, G. (1960). Calculus and analytic geometry. Massachusetts: Addison Wesley Publishing.

Vesely, D. (2004). Architecture in the age of divided representation. London: MIT Press.

Vidler, A. (2004). Architecture of the cooper union. In H. Chadwick (Ed.), Back to the school. London: Willey Academy Publications.

Whitford, F. (1991). Bauhause. London: Thames and Hudson. 